\title{
(2) OPEN ACCESS \\ Clinical characteristics, treatment and outcomes of paediatric COVID-19: a systematic review and meta-analysis
}

\author{
Omar Irfan, ${ }^{1}$ Fiona Muttalib, ${ }^{1}$ Kun Tang,${ }^{1,2}$ Li Jiang, ${ }^{1}$ Zohra S Lassi, ${ }^{3}$ \\ Zulfiqar Bhutta (i) 1,4
}

- Additional material is published online only. To view, please visit the journal online (http://dx.doi.org/10.1136/ archdischild-2020-321385).

${ }^{1}$ Centre for Global Child Health, The Hospital for Sick Children, Toronto, Ontario, Canada ${ }^{2}$ Vanke School of Public Health, Tsinghua University, Beijing, China

${ }^{3}$ Robinson Research Institute Adelaide Medical School, The University of Adelaide, Adelaide, South Australia, Australia ${ }^{4}$ Institute for Global Health \& Development, Aga Khan University, Karachi, Pakistan

\section{Correspondence to}

Dr Zulfiqar Bhutta, Centre for Global Child Health, The Hospital for Sick Children, Toronto, ON M5G 1X8, Canada; zulfiqar.bhutta@sickkids.ca

Received 11 December 2020 Revised 25 January 2021 Accepted 27 January 2021 Published Online First 16 February 2021

Check for updates

(C) Author(s) (or their employer(s)) 2021. Re-use permitted under CC BY-NC. No commercial re-use. See rights and permissions. Published by BMJ.

To cite: Irfan O, Muttalib $\mathrm{F}$ Tang K, et al. Arch Dis Child 2021;106:440-448.

\section{ABSTRACT}

Objective Compare paediatric COVID-19 disease characteristics, management and outcomes according to World Bank country income level and disease severity.

Design Systematic review and meta-analysis.

Setting Between 1 December 2019 and 8 January 2021, 3350 articles were identified. Two reviewers conducted study screening, data abstraction and quality assessment independently and in duplicate. Observational studies describing laboratory-confirmed paediatric (0-19 years old) COVID-19 were considered for inclusion.

Main outcomes and measures The pooled proportions of clinical findings, treatment and outcomes were compared according to World Bank country income level and reported disease severity.

Results 129 studies were included from 31 countries comprising 10251 children of which $57.4 \%$ were hospitalised. Mean age was 7.0 years (SD 3.6), and $27.1 \%$ had a comorbidity. Fever (63.3\%) and cough (33.7\%) were common. Of 3670 cases, $44.1 \%$ had radiographic abnormalities. The majority of cases recovered (88.9\%); however, 96 hospitalised children died. Compared with high-income countries, in lowincome and middle-income countries, a lower proportion of cases were admitted to intensive care units (ICUs) $(9.9 \%$ vs $26.0 \%)$ yet pooled proportion of deaths among hospitalised children was higher (relative risk 2.14, $95 \% \mathrm{Cl} 1.43$ to 3.20). Children with severe disease received antimicrobials, inotropes and anti-inflammatory agents more frequently than those with non-severe disease. Subgroup analyses showed that a higher proportion of children with multisystem inflammatory syndrome (MIS-C) were admitted to ICU (47.1\% vs $22.9 \%$ ) and a higher proportion of hospitalised children with MIS-C died (4.8\% vs 3.6\%) compared with the overall sample.

Conclusion Paediatric COVID-19 has a favourable prognosis. Further severe disease characterisation in children is needed globally.

\section{INTRODUCTION}

The coronavirus disease (COVID-19) pandemic caused by severe acute respiratory syndrome coronavirus-2 has spread from a local outbreak in China to a global pandemic within months. On 31 December 2019, a cluster of cases with pneumonia of unknown cause emerged from Wuhan, China. On 30 January 2020, the WHO declared the coronavirus outbreak a Public Health Emergency of
International Concern, and on 11 March 2020, a pandemic. As of 21 January 2021, there have been over 95.6 million confirmed COVID-19 cases and over 2.0 million associated deaths from 216 countries, areas or territories. ${ }^{1}$ Children under-19 years of age comprise a small proportion (1\%-10\%) of the total reported cases ${ }^{2-5}$ with a lower risk of developing critical illness from COVID-19 infection compared with adults. ${ }^{6}$ Prior systematic reviews of paediatric COVID-19 have described a mild disease in children with good outcomes. ${ }^{478}$ Since the publication of these reviews, the pandemic has spread extensively around the globe. In addition to pulmonary manifestations of COVID-19 in children, reports from Europe, North America, Latin America and Asia have emerged, describing a multisystem inflammatory syndrome children (MIS-C) related to COVID-19 infection. ${ }^{9-12}$ COVID-19 has also disrupted essential maternal and child health interventions, including outpatient visits and vaccinations for young children in most countries, further worsening the existing burden on healthcare provision and delivery. ${ }^{13}$

The objective of this review, in addition to providing a comprehensive update of the evolving paediatric COVID-19 literature, is a unique comparison of reported cases in low-income and middle-income countries (LMICs) to high-income countries (HICs) and of children with severe versus non-severe disease. Furthermore, the review provides a subgroup analysis of children presenting with symptoms of MIS-C and neonatal cases.

\section{METHODS}

The protocol of the review is registered with PROSPERO (CRD42020183134). This systematic review is reported in accordance with the Preferred Reporting Items for Systematic Reviews and Metaanalysis (PRISMA).

\section{SEARCH METHODS}

The review includes a comprehensive search of MEDLINE, Embase, WHO COVID-19 Database, Chinese COVID-19 Databases (CNKI and Wangfang), Latin-American and Caribbean Health Sciences Literature (LILACS) from 1 December 2019 to 8 January 2021. Complementary searches were conducted in Google Scholar, John Hopkins Health Resource, WHO news and the Chinese and US CDC Library. MedRxiv, BioRxiv and ChinaXiv 
were searched for preprints. No language restrictions were applied.

A search strategy was formulated and administered as shown in online supplemental table 1.

\section{STUDY SELECTION}

Observational studies reporting children (0-19 years old) with laboratory-confirmed COVID-19 (serology or RT-PCR) were considered for inclusion. Studies with a subset of children 0-19 years were included if disaggregated data for children were provided. Studies were screened for any overlap in paediatric cases by reviewing institution details and the period reported. Review articles, case reports, commentaries and letters not presenting any original data were excluded. Case reports were excluded to reduce risk of selection bias and over-representation of extreme cases. Covidence Software (2016) was used for screening by two reviewers independently and in duplicate. Key reference lists were screened for additional studies.

\section{DATA EXTRACTION}

Two reviewers conducted data extraction using a prepiloted data form. Data extracted included authors' names, date of publication, study-design, city, country, number of cases, gender, comorbidities, travel and contact history, diagnostic tests for COVID-19, clinical details, laboratory tests, radiological findings, management and outcomes. Disaggregated data by age groups ( $0-5$ years, 5-10 years and $>10$ years old) and reported disease severity was extracted where available. Criteria for severe disease were as defined within each individual study and included admission to intensive care units (ICUs), use of mechanical ventilation, multiorgan failure and presence of hypoxia (oxygen saturation $<92 \%)$.

\section{QUALITY ASSESSMENT}

Individual study quality was evaluated independently by the review authors using quality assessment tools developed by the National Heart Lung and Brain Institute (NHLBI) ${ }^{14}$ (https:// www.nhlbi.nih.gov/health-topics/study-quality-assessmenttools). Study quality was scored out of 8 , based on clarity of study objectives, case definition, consecutive inclusion of cases, comparability of included patients, definition and measurement of outcomes, length of follow-up, statistical methods and results. Studies with score 6-8 were considered to be good quality, 4-5 considered fair quality and $<4$ considered poor quality.

\section{DATA SYNTHESIS}

Categorical data were summarised as counts and proportions. The pooled proportions of reported findings were calculated using Comprehensive Meta-Analysis 2.2.027 using randomeffects model. $\mathrm{I}^{2}$ was calculated to examine statistical heterogeneity $\left(\mathrm{I}^{2}>50 \%\right.$ considered high heterogeneity). The clinical features and outcomes were compared according to (1) World Bank country income level (HICs versus LMICs) ${ }^{15}$ and (2) reported disease severity (severe versus non-severe) using pooled proportions and their 95\% CIs, supplemented by relative-risk (RR). Subgroup analyses of children with MIS-C and neonatal cases were conducted.

\section{RESULTS}

After removal of duplicates, 3350 citations were screened for inclusion. Full texts of 198 studies were screened and 129 studies $^{2}$ 3 9-12 16-138 $^{13}$ were included (online supplemental figure 1). Sixty-nine studies were excluded as they either presented overlapping data, did not provide age-disaggregated data for children or were commentaries, editorials or reviews. In terms of study setting, 13 studies were population-based national surveillance studies, 94 studies included only children admitted to hospital and 22 studies reported patients presenting to outpatient clinics or emergency departments (hospitalisation rate of $24.2 \%, 385 / 1590)$.

Sixty studies were from HICs $(n=6528)$ and 69 studies from LMICs $(n=3723)$. Almost onethird of included studies were from China (36/129, $28.0 \%),{ }^{216-333537-4345525355-577174138}$ one-fifth were from the USA $(24 / 129,18.6 \%)^{39104758606468-7079818285-879398109110115120133136}$ together comprising almost half of the included sample size $(n=4758,46.4 . \%)$. The country of origin of included studies and study characteristics are summarised in online supplemental figure 2, tables 2 and 3 .

\section{DEMOGRAPHICS AND EPIDEMIOLOGY}

A total of 9335 children from the 129 case series were included in the meta-analysis. Of 8455 children for whom initial disposition was reported, 4851 were hospitalised (57.4\%). Among them, $55.5 \%$ were men. The patient's ages ranged from 0 to 17 years with mean age of $7.0 \pm 3.6$ years. Ninety-one of the 129 studies reported age-disaggregated data for infection incidence as shown in online supplemental table 4 . Nearly half of the cases were $>10$ years of age. Contact exposure to COVID-19 was reported in $64.0 \%$ of cases. Travel history to an epicentre was reported in $13.0 \%$ cases. At-least one underlying comorbidity was reported in $27.1 \%$ of cases. The most common reported comorbidities were immunosuppression (15.8\%) and lung disease (12.5\%).

\section{CLINICAL MANIFESTATIONS}

Table 1 summarises the clinical manifestations reported in the studies. There were $13.1 \%$ asymptomatic cases (95\% CI $10.4 \%$ to $16.3 \%$ ) who presented primarily through contact exposure in family-clusters (parents, siblings and other relatives). The most common presenting symptoms were fever $(63.3 \%$, $95 \%$ CI $58.6 \%$ to $68.4 \%)$ and cough $(33.7 \%$, 95\% CI $29.6 \%$ to $38.1 \%)$ followed by nausea or vomiting $(20.0 \%$, 95\% CI $16.5 \%$ to $24.0 \%)$ and diarrhoea $(19.6 \%, 95 \%$ CI $16.1 \%$ to $23.7 \%$ ). Other symptoms included dyspnoea, nasal-symptoms, rashes, kawasaki-like symptoms, conjunctivitis, fatigue, abdominal pain and neurological symptoms. Sixty-seven of the 129 studies reported age disaggregated data for clinical features (online supplemental table 5). Clinical features were similar in the three age groups: $\leq 5$ years, $>5$ to $\leq 10$ years, $>10$ years with higher prevalence of abdominal symptoms in children $>5$ years.

\section{RADIOLOGICAL AND LABORATORY FINDINGS}

One thousand five hundred and thirty cases out of 3670 (44.1\%, $95 \%$ CI $39.5 \%$ to $48.9 \%$ ) cases had radiological abnormalities; ground glass opacities $(27.4 \%)$ were the most commonly reported abnormality.

Sixty-six studies provided details on laboratory-markers (table 2). Pooled analysis revealed increased C-Reactive Protein (CRP) $(54.2 \%, 95 \%$ CI $41.5 \%$ to $66.3 \%)$, serum-ferritin $(46.7 \%$, $95 \%$ CI $32.3 \%$ to $61.7 \%)$, lactate dehydrogenase (LDH) $(36.5 \%$, $95 \%$ CI $26.5 \%$ to $47.8 \%)$ and d-dimers $(35.2 \%, 95 \%$ CI $22.1 \%$ to $51.0 \%$ ) as the most common abnormalities. Other reported abnormalities included elevated erythrocyte sedimentation rate (ESR), lymphopaenia, procalcitonin and biomarkers for organ 
Original research

Table 1 Clinical symptoms among reported paediatric COVID-19 cases

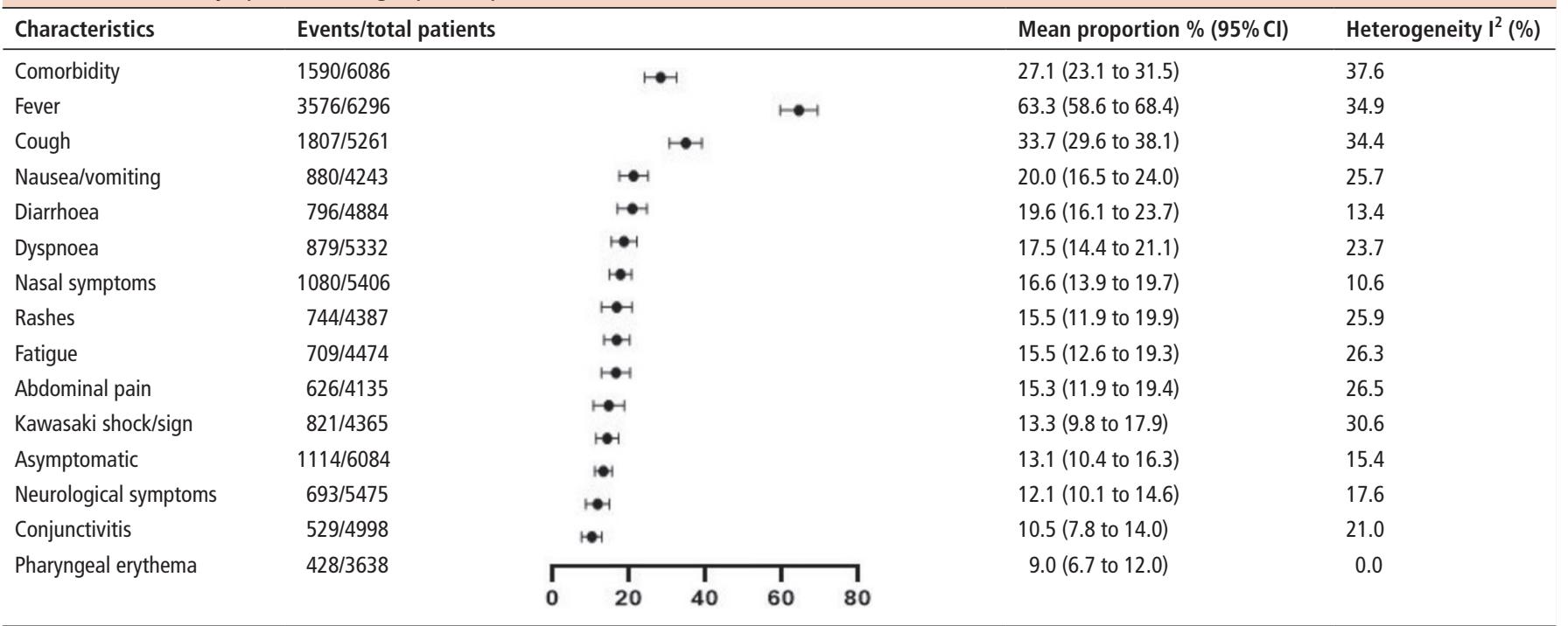

injury including elevated levels of pro B-type natriuretic peptide, troponin and creatine kinase-MB as shown in table 2.

\section{MANAGEMENT}

Details of clinical management are as shown in table 3. Commonly used therapies among hospitalised children were antimicrobials (32.2\%, 95\% CI $25.2 \%$ to $40.1 \%)$, intravenous immunoglobulin (IVIG) $(19.5 \%, 95 \%$ CI $13.5 \%$ to $27.2 \%)$ and systemic-steroids $(19.3$, 95\% CI $14.9 \%$ to $24.9 \%)$. Other treatment regimens included aspirin, inotropic drugs, inhaled interferon- $\alpha$ (IFN- $\alpha$ ), antimalarials and antivirals (ribavirin, oseltamivir, lopinavir, ritonavir and litonavir). Mechanical ventilation was provided to 490 patients $(12.2 \%$, 95\% CI $9.7 \%$ to $15.3 \%)$.

\section{PROGNOSIS AND SEVERE CASES}

One thousand three hundred and fifty-nine patients $(22.9 \%$, $95 \%$ CI $17.6 \%$ to $29.2 \%$ ) were admitted to ICUs (table 3 ). Thirty-eight studies provided disaggregated data for severe cases (table 4). A higher proportion of children with severe disease had symptoms consistent with MIS-C and received antimicrobials, inotropes and anti-inflammatory agents compared with those with non-severe disease. There were no deaths among children

Table 2 Laboratory and radiological features among reported paediatric COVID-19 cases

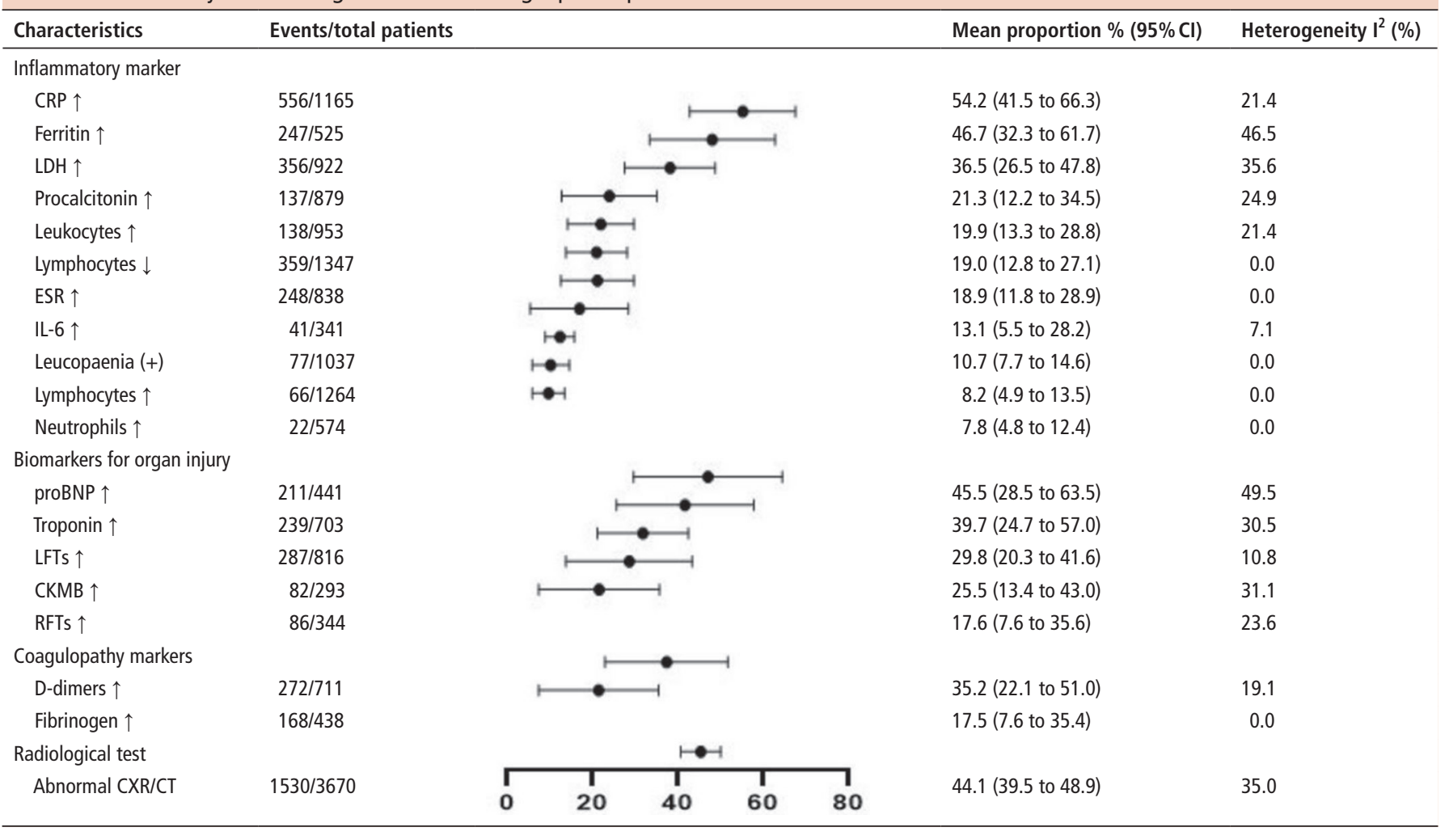


Original research

Table 3 Clinical management and outcomes among reported paediatric COVID-19 cases

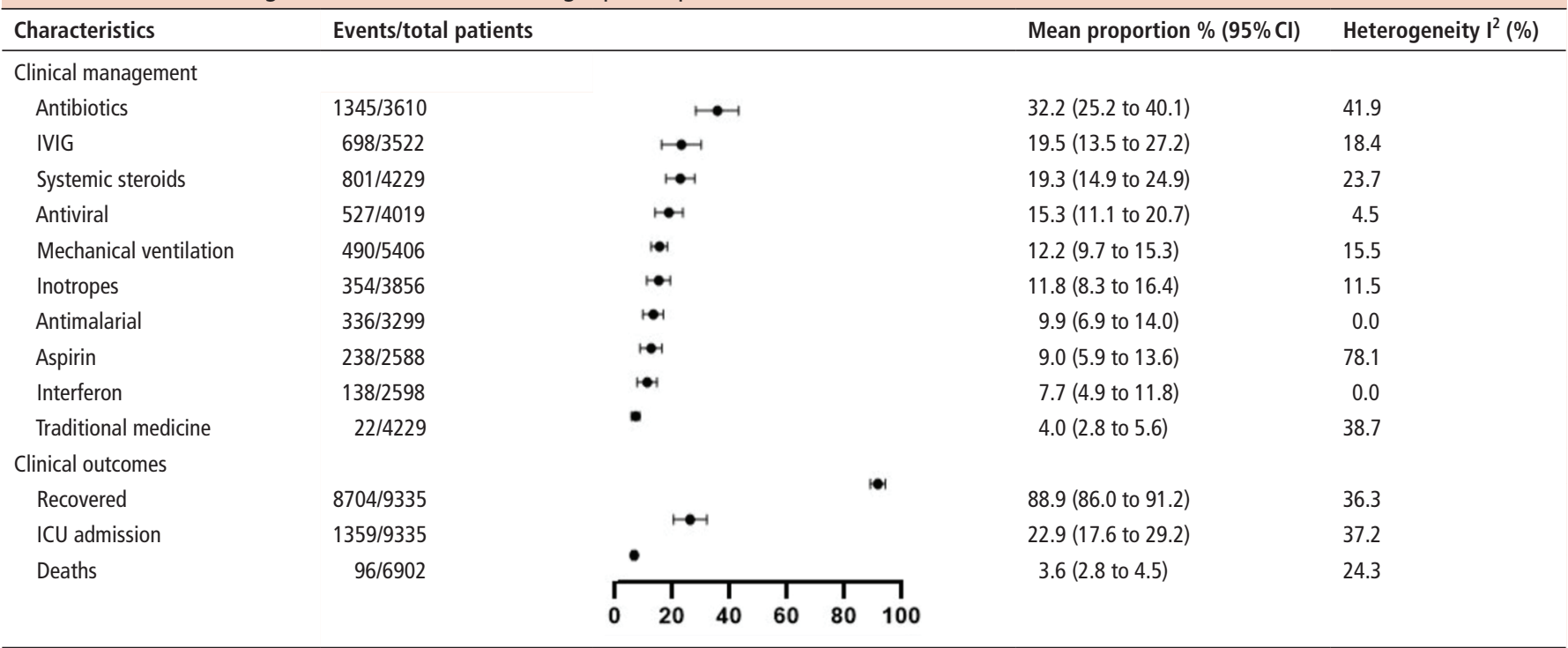

ICU, intensive care unit; IVIG, intravenous immunoglobulin.

Table 4 Comparison of clinical symptoms, management and outcomes among reported paediatric COVID-19 non-severe ( $n=2402$ cases, 64 studies) and severe ( $n=796$ cases, 38 studies) cases

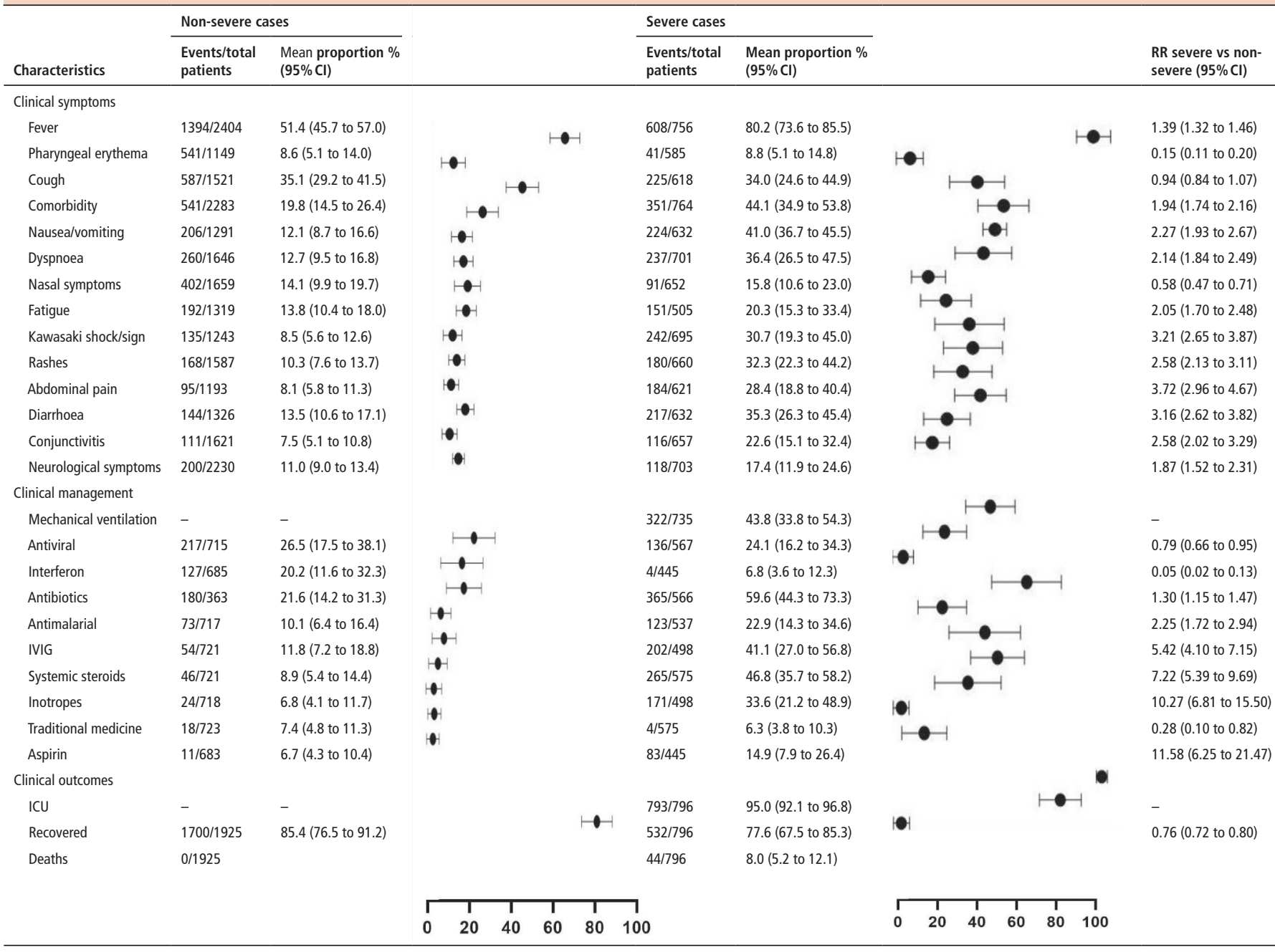

ICU, intensive care unit; IVIG, intravenous immunoglobulin. 
Table 5 Comparison of clinical symptoms, management and outcomes among reported paediatric COVID-19 cases in HICs ( $\mathrm{n}=5641$ cases, 60 studies) and LMICs ( $\mathrm{n}=3694,69$ studies)

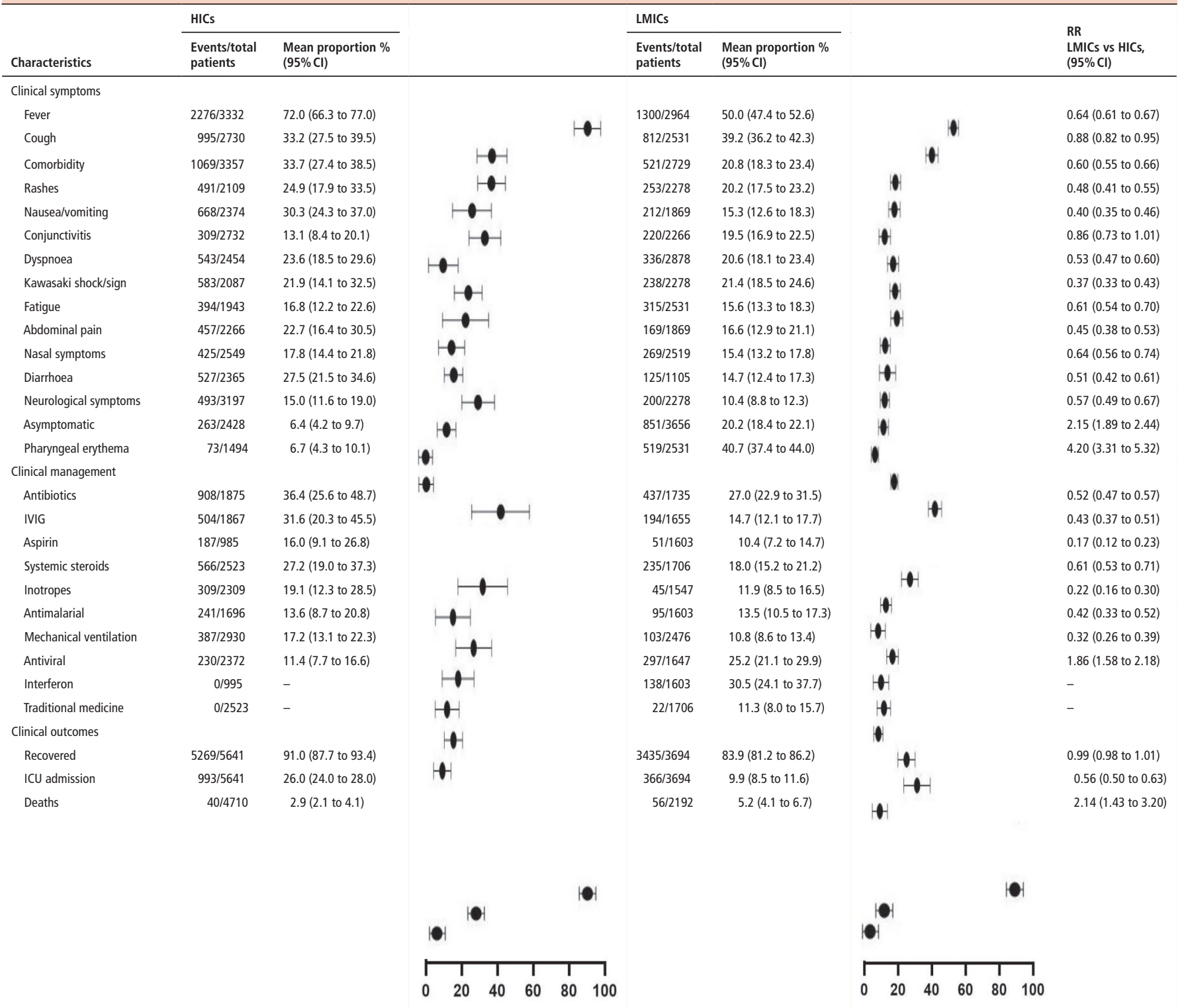

HICS, high-income countries; ICU, intensive care unit; IVIG, intravenous immunoglobulin; LMICs, low-income and middle-income countries; RR, relative risk.

categorised as non-severe and 44 deaths among severe cases, where disaggregated data were provided. Hospital outcomes were reported for 9335 children; 8704 cases $(88.9 \%, 95 \%$ CI $86.0 \%$ to $91.2 \%$ ) were definitively discharged, 96 died and remaining children either remained hospitalised at the time of reporting or were readmitted.

\section{COMPARISON OF OUTCOMES ACCORDING TO WORLD BANK COUNTRY CLASSIFICATION}

Of the included studies that reported clinical characteristics and outcomes, 60 studies were from HICs $(n=6528)$ and 69 studies from LMICs $(n=3723)$ as show in table 5. Studies in LMICs included a higher proportion of hospitalised children (1981/3723, 53.2\%) compared with HIC studies (2897/6528, 44.4\%). Abdominal symptoms and symptoms consistent with MIS-C were more frequently reported in HICs. A lower proportion of children in LMICs were admitted to the ICU (RR 0.56,
95\% CI 0.50 to $0.63, \mathrm{p}<0.05$ ), mechanically ventilated (RR $0.32,95 \%$ CI 0.26 to $0.39, \mathrm{p}<0.05$ ) and treated with different therapies; inotropes, antimicrobials, steroids, aspirin and IVIG. Only children in LMICs received inhaled IFN- $\alpha$. Among the hospitalised cases, 40 deaths were reported in HICs compared with 56 in LMICs (pooled proportion 2.9\% vs 5.2\%). Riskadjusted mortality according to severity of illness could not be calculated due to lack of data (table 5).

\section{SUBGROUP ANALYSES OF CHILDREN PRESENTING WITH MIS-C, AND COVID-19 IN NEONATES}

Thirty-one studies $(n=1208)$ with 22 from HIC $(n=602)$, reported series of children presenting with MIS-C. Fever, abdominal pain and diarrhoea were the most common symptoms. Nearly half of children $(638 / 1208)$ who met criteria for MIS-C were admitted to ICU (449/638, 70.3\% of which were from HIC) compared with $22.9 \%$ in the overall analysis (online supplemental tables 6 and 7). 
Disaggregated data were available on 184 neonates with fever; inability to feed/lethargy and dyspnoea were the most commonly reported symptoms. Twenty-one neonates $(16.6 \%$, $95 \%$ CI $11.2 \%$ to $23.9 \%$ ) were asymptomatic at the time of diagnosis.

\section{QUALITY ASSESSMENT OF INCLUDED STUDIES}

One hundred and twenty-one studies were determined to be of good quality while eight were of fair quality (online supplemental table 8). Studies were primarily downgraded for incomplete case definition, $2931444648-50130135138$ incomplete case follow-up, $10232426293235445153778285909499106112-114120130$ 135-137 missing data 23 19-21 $293542-445257748992-94117128$ and nonconsecutive patient enrolment, ${ }^{9} 1112$ 16 18-26 28 30-35 37-39 50 57 61-73 $80828789-919395102109110112114123125126129$ 134-136 which raises concern that the included sample could be biased towards more severe presentations.

\section{DISCUSSION}

Global knowledge of COVID-19 epidemiology, clinical characteristics and management has continued to evolve since the onset of the pandemic. Children have been noted to have relatively lower rates of severe illness and low mortality; however, they have been impacted by MIS-C. ${ }^{4} 39$

The findings of our review, the largest in terms of published systematic reviews on paediatric COVID-19, are consistent with previous reviews that identified predominance of infection in school-age children, slight male predisposition, prevalence of comorbidities among children with COVID-19 and low hospitalisation and mortality rates. ${ }^{24} 140$ The clinical presentation in children is heterogeneous, including a wide spectrum of clinical features. Fever and cough were the most commonly reported presenting symptoms, in line with the previously published systematic reviews. ${ }^{441} \mathrm{~A}$ U-shaped curve of severity has been demonstrated in children diagnosed with COVID-19 with infants under 1 year of age and adolescents 10-14 years of age at higher risk of developing severe COVID-19. ${ }^{3475}$ Due to lack of age-disaggregated data, we could not reliably compare the frequency of severe cases by age group in this review. Reported risk factors for severe disease among children include age, viral $\operatorname{load}^{142}$ and presence of comorbidities. ${ }^{3}$ There is a possibility that children with comorbidities may have been hospitalised related to their underlying chronic condition and incidentally determined to have COVID-19 infection or investigated more extensively. Some of the common comorbidities reported in children with COVID-19 infection include asthma, immunosuppression, congenital heart disease, kidney disease and obesity. ${ }^{347}$

Regional differences were identified in the comparison of clinical features, treatment and outcomes between HICs and LMICs. Pooled estimates of hospital mortality were higher in LMICs compared with HICs. Given that it was not possible to calculate risk-adjusted mortality rates for COVID-19, it is unclear whether observed differences in mortality are related to selection bias (eg, differences in severity of illness of included patients or differences in case definitions and inclusion criteria) or differences in available hospital resources. Nevertheless, there is ongoing concern that, in LMICs with high burden of illness and health system limitations, children with severe disease and MIS-C may be at greater risk for adverse outcomes and death than perceived to date. The differences in frequency of observed clinical features may be related to increasing recognition of MIS-C over the course of the pandemic and their inclusion in more recent COVID-19 case series, but is likely similar between HICs and LMICs.

Comparisons of clinical features and outcomes according to severity of illness were limited by heterogeneous reporting across the included case series. A higher proportion of children with severe disease demonstrated symptoms consistent with MIS-C (fever, abdominal symptoms, rash, neurological symptoms, conjunctivitis) and received IVIG, steroids and inotropes.

Compared with previous reviews, several at an earlier stage of the pandemic, ${ }^{478140143}$ this review has several strengths. Using a broad search strategy implemented in English, Chinese and Spanish databases, we summarise evidence from 129 studies from 31 different countries, the largest sample to-date. We excluded case reports to minimise selective reporting of extreme and atypical cases. We also attempted to reduce possible overlap in cases to prevent duplications. We identified differences in features from studies in HICs compared with LMICs, and between severe and non-severe cases, although with limited available data. Finally, we report subgroup analyses for neonates, and children presenting with MIS-C.

The review is limited primarily by the small sample sizes of individual studies, limitations in study reporting, and study quality limitations due to non-consecutive patient enrolment, unclear case definition and incomplete follow-up to hospital discharge. Our approach of pooling proportions is subject to bias and wide confidence-intervals due to small study sample size. We could not undertake multivariate analysis to identify risk factors for severe infection or adverse outcome in children due to lack of individual-patient-data. The inclusion of asymptomatic cases could have contributed to underestimation of the prevalence of clinical characteristics and optimism in the reporting of outcomes. Finally, it should be noted that a large number $(36 / 129,28.0 \%)$ of the included studies were from China. While the Chinese healthcare system is well-resourced in certain regions, many of the Chinese studies included were conducted in the city of Wuhan or in Hubei Province $(n=9,32.1 \%)$, where the gross domestic product per capita is less than half of that of Beijing and Shanghai. ${ }^{144}$ Therefore, the findings of studies from China may be generalisable to the socioeconomic and health development status of other middle-income countries.

This review contributes to the global understanding of paediatric COVID-19 disease and supports priority setting in research for current pandemic and future outbreaks. This body of literature would be improved by complete reporting of larger series with consecutive recruitment of patients, specific case definitions and complete long-term follow-up to determine global epidemiological trends, age-specific burden of disease and illness trajectory following COVID-19 infection. Improved characterisation of disease severity and increased reports from low-income countries are needed to better understand differences in clinical manifestations, resource utilisation and outcome by region, which can be integrated in future updated analyses. The concern for selection bias remains as it is possible that in LMICs, the population of hospitalised children was sicker and at higher baseline risk of death, independent of resources. Individual-patient-data meta-analysis would be of benefit to characterise risk factors for severe disease, clinical features in different age groups and account for observed differences in outcome. With respect to clinical management, none of the therapies instituted in the treatment of children with severe COVID-19 disease have been demonstrated to improve outcome in randomised trials; therefore, a recommendation regarding their use is challenging. Given that children appear less likely to develop severe respiratory disease, but are at risk of multiorgan dysfunction due to MIS-C, 
further studies are needed to characterise the clinical trajectory of this novel syndrome and determine the optimal treatment for it. Finally, there remains paucity of studies reporting long-term prognosis of COVID-19 in children. ${ }^{145}$

\section{CONCLUSION}

Our review suggests that children predominantly contracted mild form of infection but could be at risk of more severe outcomes. It is crucial to take into consideration risk factors including contactexposure, underlying comorbidities, young age and male sex which may increase the risk of severe disease. While we have identified several elements that highlight the disease spectrum and higher risk of adverse outcomes in certain settings, such as LMICs, there is the need for much closer scrutiny of this illness globally with individual patient data analysis.

Contributors ZB conceptualised the study and secured funding. ZSL and OI drafted the study protocol, conducted the literature search, study screening, selection and data extraction and drafted the manuscript. LJ and KT designed the data collection instruments, collected data, carried out data analyses and reviewed and revised the manuscript. FM drafted the initial manuscript and reviewed and revised the manuscript. All authors critically reviewed the manuscript for important intellectual content and approved the final manuscript as submitted. ZB is the guarantor.

Funding This review was funded in part by a grant from UNICEF (Headquarters) in partnership with the International Pediatric Association and with core support from the Centre for Global Child Health (Toronto) and the Center of Excellence in Women \& Child Health, The Aga Khan University, Karachi, Pakistan

\section{Competing interests None declared.}

Patient consent for publication Not required.

Provenance and peer review Not commissioned; internally peer reviewed. Data availability statement Data are available upon request

Supplemental material This content has been supplied by the author(s). It has not been vetted by BMJ Publishing Group Limited (BMJ) and may not have been peer-reviewed. Any opinions or recommendations discussed are solely those of the author(s) and are not endorsed by BMJ. BMJ disclaims all liability and responsibility arising from any reliance placed on the content. Where the content includes any translated material, BMJ does not warrant the accuracy and reliability of the translations (including but not limited to local regulations, clinical guidelines, terminology, drug names and drug dosages), and is not responsible for any error and/or omissions arising from translation and adaptation or otherwise.

Open access This is an open access article distributed in accordance with the Creative Commons Attribution Non Commercial (CC BY-NC 4.0) license, which permits others to distribute, remix, adapt, build upon this work non-commercially, and license their derivative works on different terms, provided the original work is properly cited, appropriate credit is given, any changes made indicated, and the use is non-commercial. See: http://creativecommons.org/licenses/by-nc/4.0/.

\section{ORCID iD}

Zulfiqar Bhutta http://orcid.org/0000-0003-0637-599X

\section{REFERENCES}

1 WHO. Who coronavirus disease (COVID-19) Dashboard data last updated: 2021/1/21. Available: https://covid19. who.int/

2 Dong Y, Mo X, Hu Y. Epidemiological characteristics of 2143 pediatric patients with 2019 coronavirus disease in China. J Emerg Med 2020;58:712-3.

3 Covid CD CC, COVID C, Bialek S, et al. Coronavirus Disease 2019 in Children - United States, February 12-April 2, 2020. MMWR Morb Mortal Wkly Rep 2020;69:422.

4 Hoang A, Chorath K, Moreira A, et al. COVID-19 in 7780 pediatric patients: a systematic review. EClinicalMedicine 2020;24:100433.

5 AAP. Children and COVID19: state data report 28/8/2020, 2020.

6 Wang E, Brar K. COVID-19 in children: an epidemiology study from China. J Allergy Clin Immunol 2020;8:2118-20

7 de Souza TH, Nadal JA, Nogueira RJN, et al. Clinical manifestations of children with COVID-19: a systematic review. Pediatr Pulmonol 2020;55:1892-9.

8 Castagnoli R, Votto M, Licari A, et al. Severe acute respiratory syndrome coronavirus 2 (SARS-CoV-2) infection in children and adolescents. JAMA Pediatr 2020;174:882.

9 Cheung EW, Zachariah P, Gorelik M, et al. Multisystem inflammatory syndrome related to COVID-19 in previously healthy children and adolescents in New York City. JAMA 2020;324:294.
10 Feldstein LR, Rose EB, Horwitz SM, et al. Multisystem inflammatory syndrome in U.S. children and adolescents. N Engl J Med Overseas Ed 2020;383:334-46.

11 Blondiaux E, Parisot P, Redheuil A, et al. Cardiac MRI in children with multisystem inflammatory syndrome associated with COVID-19. Radiology 2020;297:E283-8.

12 Pouletty M, Borocco C, Ouldali N, et al. Paediatric multisystem inflammatory syndrome temporally associated with SARS-CoV-2 mimicking Kawasaki disease (Kawa-COVID-19): a multicentre cohort. Ann Rheum Dis 2020;79:999-1006.

13 Global Financing Facility for Women, Children and Adolescents (GFF)- September 18, 2020. Available: https://www.globalfinancingfacility.org/new-findings-confirmglobal-disruptions-essential-health-services-women-and-children-covid-19

14 National Heart L, and Blood Institute. Quality assessment tool for observational cohort and cross-sectional studies. Bethesda: National Institutes of health, department of health and human services, 2014.

15 Group WB. World bank country and lending groups (country classification), 2020.

16 Qiu H, Wu J, Hong L, et al. Clinical and epidemiological features of 36 children with coronavirus disease 2019 (COVID-19) in Zhejiang, China: an observational cohort study. Lancet Infect Dis 2020;20:689-96.

17 Wang D, Ju XL, Xie F, et al. [Clinical analysis of 31 cases of 2019 novel coronavirus infection in children from six provinces (autonomous region) of northern China]. Zhonghua Er Ke Za Zhi 2020;58:E011-E.

18 Zheng F, Liao C, Fan Q-H, et al. Clinical characteristics of children with coronavirus disease 2019 in Hubei, China. Curr Med Sci 2020;40:275-80.

19 Xia W, Shao J, Guo Y, et al. Clinical and CT features in pediatric patients with COVID-19 infection: different points from adults. Pediatr Pulmonol 2020;55:1169-74.

20 Feng K, Yun YX, Wang XF, et al. [Analysis of CT features of 15 Children with 2019 novel coronavirus infection]. Zhonghua Er Ke Za Zhi 2020;58:E007.

21 Jiehao C, Jin X, Daojiong L, et al. A case series of children with 2019 novel coronavirus infection: clinical and epidemiological features. Clin Infect Dis 2020;71:1547-51.

22 Wei M, Yuan J, Liu Y, et al. Novel coronavirus infection in hospitalized infants under 1 year of age in China. JAMA 2020;323:1313-4.

$23 \mathrm{Su} \mathrm{L}, \mathrm{Ma} \mathrm{X}, \mathrm{Yu} \mathrm{H}$, et al. The different clinical characteristics of corona virus disease cases between children and their families in China - the character of children with COVID-19. Emerg Microbes Infect 2020;9:707-13.

24 Zhou Y, Yang G-D, Feng K, et al. [Clinical features and chest CT findings of coronavirus disease 2019 in infants and young children]. Zhongguo Dang Dai Er Ke Za Zhi 2020;22:215-20.

25 Sun D, Li H, Lu X-X, et al. Clinical features of severe pediatric patients with coronavirus disease 2019 in Wuhan: a single center's observational study. World I Pediatr 2020;16:251-9.

26 Liu W, Zhang Q, Chen J, et al. Detection of Covid-19 in children in early January 2020 in Wuhan, China. N Engl J Med 2020;382:1370-1.

27 Hu Z, Song C, Xu C, et al. Clinical characteristics of 24 asymptomatic infections with COVID-19 screened among close contacts in Nanjing, China. Sci China Life Sci 2020;63:706-11

28 Liu M, Song Z, Xiao K. High-Resolution computed tomography manifestations of 5 pediatric patients with 2019 novel coronavirus. I Comput Assist Tomogr 2020;44:311-3.

29 Liu H, Liu F, Li J, et al. Clinical and CT imaging features of the COVID-19 pneumonia: focus on pregnant women and children. J Infect 2020;80:e7-e13.

30 Lou XX, Shi CX, Zhou CC, et al. Three children who recovered from novel coronavirus 2019 pneumonia. J Paediatr Child Health 2020:56:650-651.

31 Zhang T, Cui X, Zhao X, et al. Detectable SARS-CoV-2 viral RNA in feces of three children during recovery period of COVID-19 pneumonia. J Med Virol 2020;92:909-14.

32 Li Y, Guo F, Cao Y, et al. Insight into COVID-2019 for pediatricians. Pediatr Pulmonol 2020;55:E1-4.

33 Ji L-N, Chao S, Wang Y-J, et al. Clinical features of pediatric patients with COVID-19: a report of two family cluster cases. World J Pediatr 2020;16:267-70.

34 Tagarro A, Epalza C, Santos M, et al. Screening and severity of coronavirus disease 2019 (COVID-19) in children in Madrid, Spain. JAMA Pediatr 2020. doi:10.1001/ jamapediatrics.2020.1346. [Epub ahead of print: 08 Apr 2020].

35 Chen A, Huang J-xiang, Liao Y, et al. Differences in clinical and imaging presentation of pediatric patients with COVID-19 in comparison with adults. Radiology 2020;2:e200117.

36 See KC, Liew SM, Ng DCE, et al. COVID-19: four paediatric cases in Malaysia. Int J Infect Dis 2020;94:125-7.

37 Zhang G-X, Zhang A-M, Huang L, et al. [Twin girls infected with SARS-CoV-2]. Zhongguo Dang Dai Er Ke Za Zhi 2020;22:221-5.

38 Cheng. A case report of two children with corona virus disease 2019 complicated with diffuse intravascular coagulation, 2020.

39 Tang A, Xu W, Chen P. A retrospective study of the clinical characteristics of COVID-19 infection in 26 children. medRxiv 2020.

40 Zhu L, Wang J, Huang R, et al. Clinical characteristics of a case series of children with coronavirus disease 2019. Pediatr Pulmonol 2020;55:1430-2. 
41 Tan X, Huang J, Zhao F, et al. [Clinical features of children with SARS-CoV-2 infection: an analysis of 13 cases from Changsha, China]. Zhongguo Dang Dai Er Ke Za Zhi 2020;22:294.

$42 \mathrm{Ma} \mathrm{H}$, Shao J, Wang Y. High resolution CT features of COVID-19 in children. Chinese Journal of Radiology 2020;54.

43 Shen Q, Guo W, Guo T, et al. Novel coronavirus infection in children outside of Wuhan, China. Pediatr Pulmonol 2020;55:1424-9.

44 Schwierzeck V, König JC, Kühn J, et al. First reported nosocomial outbreak of severe acute respiratory syndrome coronavirus 2 (SARS-CoV-2) in a pediatric dialysis unit. Clin Infect Dis 2020. doi:10.1093/cid/ciaa491. [Epub ahead of print: 27 Apr 2020].

45 Jiang J, Duan L, Xiong D. Epidemiological and clinical characteristics of novel coronavirus infection in children: thoughts on the diagnostic criteria of suspected cases outside Hubei Province. Chinese Pediatric Emergency Medicine 2020.

46 Riphagen S, Gomez X, Gonzalez-Martinez C, et al. Hyperinflammatory shock in children during COVID-19 pandemic. The Lancet 2020;395:1607-8.

47 Shekerdemian LS, Mahmood NR, Wolfe KK, et al. Characteristics and outcomes of children with coronavirus disease 2019 (COVID-19) infection admitted to US and Canadian pediatric intensive care units. JAMA Pediatr 2020;174:868.

48 Verdoni L, Mazza A, Gervasoni A, et al. An outbreak of severe Kawasaki-like disease at the Italian epicentre of the SARS-CoV-2 epidemic: an observational cohort study. The Lancet 2020;395:1771-8.

49 Rahimzadeh G, Ekrami Noghabi M, Kadkhodaei Elyaderani F, et al. COVID-19 infection in Iranian children: a case series of 9 patients. J Pediatr Rev 2020:8:139-44.

50 Tullie L, Ford K, Bisharat M, et al. Gastrointestinal features in children with COVID-19: an observation of varied presentation in eight children. Lancet Child Adolesc Health 2020;4:e19-20.

51 Sajid MI, Altaf S, Mushtaq N. A wrinkle in time: how has management of pediatric cancers changed during COVID-19 in Pakistan? 2020.

52 Zhang Z-J, Yu X-J, Fu T, et al. Novel coronavirus infection in newborn babies aged $<28$ days in China. Eur Respir J 2020;55:2000697.

53 Zeng L, Xia S, Yuan W, et al. Neonatal early-onset infection with SARS-CoV-2 in 33 neonates born to mothers with COVID-19 in Wuhan, China. JAMA Pediat 2020;174:722.

54 Salvatori G, De Rose DU, Concato C, et al. Managing COVID-19-Positive maternalinfant dyads: an Italian experience. Breastfeed Med 2020;15:347-8.

55 Zhang XMY, Xiao J, Zhang Z. Clinical characteristics of novel coronavirus pneumonia in children in Jinan.

56 Wu H-P, Li B-F, Chen X, et al. [Clinical features of coronavirus disease 2019 in children aged $<18$ years in Jiangxi, China: an analysis of 23 cases]. Zhongguo Dang Dai Er Ke Za Zhi 2020:22:419-24.

57 Zhang H-Y, Zhang Y. [Coronavirus disease 2019 and hypertension in 2 children] Zhongguo Dang Dai Er Ke Za Zhi 2020;22:425-8.

58 Chao JY, Derespina KR, Herold BC, et al. Clinical characteristics and outcomes of hospitalized and critically ill children and adolescents with coronavirus disease 2019 at a tertiary care medical center in New York City. J Pediatr 2020;223:14-19.

59 Eghbali ASS, Sadat N, et al. COVID-19 in pediatric patients: a case series. J Cell Mol Med 2020;5:3-5.

60 Chiotos K, Bassiri H, Behrens EM, et al. Multisystem inflammatory syndrome in children during the coronavirus 2019 pandemic: a case series. J Pediatric Infect Dis Soc 2020;9:393-8.

61 Flores V, Miranda R, Merino L, et al. SARS-CoV-2 infection in children with febrile neutropenia. Ann Hematol 2020;99:1-2.

62 García-Salido A, Leoz-Gordillo I, Martínez de Azagra-Garde A, et al. Children in critical care due to severe acute respiratory syndrome coronavirus 2 infection: experience in a Spanish hospital. Pediatr Crit Care Med 2020;21:e576-e580.

63 Cabrero-Hernández M, García-Salido A, Leoz-Gordillo I, et al. Severe SARS-CoV-2 infection in children with suspected acute abdomen: a case series from a tertiary hospital in Spain. Pediatr Infect Dis J 2020;39:e195-8.

64 Waltuch T, Gill P, Zinns LE, et al. Features of COVID-19 post-infectious cytokine release syndrome in children presenting to the emergency department. Am J Emerg Med 2020:38:2246.e3-2246.e6.

65 Kakuya F, Okubo H, Fujiyasu $\mathrm{H}$, et al. The first pediatric patients with coronavirus disease 2019 (COVID-19) in Japan: risk of co-infection with other respiratory viruses. Jpn J Infect Dis 2020:73:377-80.

66 Soltani J, Sedighi I, Shalchi Z, et al. Pediatric coronavirus disease 2019 (COVID-19): an insight from West of Iran. North Clin Istanb 2020;7:284.

67 Toubiana J, Poirault C, Corsia A, et al. Kawasaki-like multisystem inflammatory syndrome in children during the covid-19 pandemic in Paris, France: prospective observational study. BMJ 2020;369:m2094.

68 Foster CE, Moulton EA, Munoz FM, et al. Coronavirus disease 2019 in children Cared for at Texas children's Hospital: initial clinical characteristics and outcomes. J Pediatric Infect Dis Soc 2020;9:373-7.

69 White A, Mukherjee P, Stremming J, et al. Neonates hospitalized with communityacquired SARS-CoV-2 in a Colorado neonatal intensive care unit. Neonatology 2021:117:641-5.
70 Parri N, Lenge M, Cantoni B, et al. COVID-19 in 17 Italian pediatric emergency departments. Pediatrics 2020;146. doi:10.1542/peds.2020-1235. [Epub ahead of print: 23 Sep 2020].

71 Gao Y, Zhang D, Sui S, et al. Clinical features and treatment protocol in eleven Chinese children with mild COVID-19. Indian J Pediatr 2020;87:748.

72 Harman K, Verma A, Cook J, et al. Ethnicity and COVID-19 in children with comorbidities. Lancet Child Adolesc Health 2020;4:e24-5.

73 Whittaker E, Bamford A, Kenny J, et al. Clinical characteristics of 58 children with a pediatric inflammatory multisystem syndrome temporally associated with SARSCoV-2. JAMA 2020;324:259.

74 Lu X, Zhang L, Du H. SARS-CoV-2 infection in children. N Engl J Med 2000;382.

75 Götzinger F, Santiago-García B, Noguera-Julián A, et al. COVID-19 in children and adolescents in Europe: a multinational, multicentre cohort study. Lancet Child Adolesc Health 2020;4:653-61

76 Parri N, Lenge M, Buonsenso D. Children with Covid-19 in pediatric emergency departments in Italy. N Eng/ J Med Overseas Ed 2020;383:187-90.

77 Abdel-Mannan O, Eyre M, Löbel U, et al. Neurologic and radiographic findings associated with COVID-19 infection in children. JAMA Neurol 2020. doi:10.1001/ jamaneurol.2020.2687. [Epub ahead of print: $01 \mathrm{Jul} 2020$ ].

78 Banerjee S, Guha A, Das A, et al. A preliminary report of COVID-19 in children in India. Indian Pediatr 2020;57:963-4.

79 Bhumbra S, Malin S, Kirkpatrick L, et al. Clinical features of critical coronavirus disease 2019 in children. Pediatr Crit Care Med 2020;21:e948-e953.

80 Bisogno G, Provenzi M, Zama D. Clinical characteristics and outcome of SARS-CoV-2 infection in Italian pediatric oncology patients: a study from the infectious diseases Working group of the AIEOP. J Pediatric Infect Dis Soc 2020

81 Blumfield E, Levin TL. COVID-19 in pediatric patients: a case series from the Bronx, NY. Pediatr Radiol 2020:50:1369-74.

82 Derespina KR, Kaushik S, Plichta A, et al. Clinical manifestations and outcomes of critically ill children and adolescents with coronavirus disease 2019 in New York City. J Pediatr 2020;22610.1016/j.jpeds.2020.07.039. [Epub ahead of print: $16 \mathrm{Ju}$ 2020]

83 George S, Ansari MS, Kalliath A. COVID-19 in children in Brunei Darussalam: higher incidence but mild manifestations. J Med Virol 2020.

84 González Cortés R, García-Salido A, Roca Pascual D, et al. A multicenter nationa survey of children with SARS-CoV-2 infection admitted to Spanish pediatric intensive care units. Intensive Care Med 2020;46:1774-6.

85 Kainth MK, Goenka PK, Williamson KA, et al. Early experience of COVID-19 in a US children's Hospital. Pediatrics 2020;146:e2020003186.

86 Kaushik S, Aydin SI, Derespina KR, et al. Multisystem inflammatory syndrome in children associated with severe acute respiratory syndrome coronavirus 2 infection (MIS-C): a multi-institutional study from New York City. J Pediatr 2020:224:24-9.

87 Kest H, Kaushik A, DeBruin W. Multisystem inflammatory syndrome in children (MIS-C) associated with 2019 novel coronavirus (SARS-CoV-2) infection. Case Rep Pediatr 2020;2020:1-4.

88 Korkmaz MF, Türe E, Dorum BA, et al. The epidemiological and clinical characteristics of 81 children with COVID-19 in a pandemic hospital in turkey: an observational cohort study. J Korean Med Sci 2020;35:e236.

89 Meslin P, Guiomard C, Chouakria M, et al. Coronavirus disease 2019 in newborns and very young infants: a series of six patients in France. Pediatr Infect Dis $J$ 2020:39:e145-7.

90 Moraleda C, Serna-Pascual M, Soriano-Arandes A, et al. Multi-Inflammatory syndrome in children related to SARS-CoV-2 in Spain. Clin Infect Dis 2020. doi:10.1093/cid/ciaa1042. [Epub ahead of print: 25 Jul 2020].

91 KF N, Kothari T, Bandi S. COVID-19 multisystem inflammatory syndrome in three teenagers with confirmed SARS-CoV-2 infection. J Med Virol 2020;92.

92 Paquette D, Bell C, Roy M, et al. Laboratory-confirmed COVID-19 in children and youth in Canada, January 15-April 27, 2020. Can Commun Dis Rep 2020;46:121-4

93 Perez A, Kogan-Liberman D, Sheflin-Findling S. Presentation of severe acute respiratory syndrome-coronavirus 2 infection as cholestatic jaundice in two healthy adolescents. J Pediatr 2020. doi:10.1016/j.jpeds.2020.07.054. [Epub ahead of print: 23 Jul 2020].

94 Sarangi B, Reddy VS, Oswal JS, et al. Epidemiological and clinical characteristics of COVID-19 in Indian children in the initial phase of the pandemic. Indian Pediatr 2020;57:914-7

95 Sadiq M, Aziz OA, Kazmi U, et al. Multisystem inflammatory syndrome associated with COVID-19 in children in Pakistan. Lancet Child Adolesc Health 2020;4:e36-7.

96 Swann OV, Holden KA, Turtle L, et al. Clinical characteristics of children and young people admitted to hospital with covid-19 in United Kingdom: prospective multicentre observational cohort study. BMJ 2020;370:m3249.

97 Antúnez-Montes OY, Escamilla MI, Figueroa-Uribe AF, et al. COVID-19 and multisystem inflammatory syndrome in Latin American children. Pediatr Infect Dis 2020:Publish Ahead of Print.

98 Capone CA, Subramony A, Sweberg T, et al. Characteristics, cardiac involvement, and outcomes of multisystem inflammatory syndrome of childhood associated 
with severe acute respiratory syndrome coronavirus 2 infection. J Pediatr 2020;224:141-5

99 Cura Yayla BC, Özsürekçi Y, Aykaç K, et al. Characteristics and management of children with COVID-19 in turkey. Balkan Med J 2020;37:341-7.

100 Davies P, Evans C, Kanthimathinathan HK, et al. Intensive care admissions of children with paediatric inflammatory multisystem syndrome temporally associated with SARS-CoV-2 (PIMS-TS) in the UK: a multicentre observational study. Lancet Child Adolesc Health 2020;4:669-77.

101 de Farias ECF, Pedro Piva J, de Mello MLFMF, et al. Multisystem inflammatory syndrome associated with coronavirus disease in children: a Multi-centered study in Belém, Pará, Brazil. Pediatr Infect Dis J 2020;39:e374-e376.

102 Dima M, Enatescu I, Craina M, et al. First neonates with severe acute respiratory syndrome coronavirus 2 infection in Romania: three case reports. Medicine 2020;99:e21284

103 Klompas M, Baker MA, Rhee C. Airborne transmission of SARS-CoV-2: theoretical considerations and available evidence. JAMA 2020.

104 Ibrahim LF, Tosif S, McNab S, et al. SARS-CoV-2 testing and outcomes in the first 30 days after the first case of COVID-19 at an Australian children's hospital. Emerg Med Australas 2020;32:801-8.

105 Kilani MM, Odeh MM, Shalabi M, et al. Clinical and laboratory characteristics of SARS-CoV2-infected paediatric patients in Jordan: serial RT-PCR testing until discharge. Paediatr Int Child Health 2020:1-10.

106 Okarska-Napierała M, Ludwikowska KM, Szenborn L, et al. Pediatric inflammatory multisystem syndrome (PIMS) did occur in Poland during months with low COVID-19 prevalence, preliminary results of a nationwide register. J Clin Med 2020;9. doi:10.3390/jcm9113386. [Epub ahead of print: 22 Oct 2020].

107 Mahmoudi S, Mehdizadeh M, Shervin Badv R, et al. The coronavirus disease 2019 (COVID-19) in children: a study in an Iranian children's referral hospital. Infect Drug Resist 2020;13:2649-55.

108 Mamishi S, Movahedi Z, Mohammadi M, et al. Multisystem inflammatory syndrome associated with SARS-CoV-2 infection in 45 children: a first report from Iran. Epidemiol Infect 2020;148:e196.

109 Mithal LB, Machut KZ, Muller WJ, et al. SARS-CoV-2 Infection in Infants Less than 90 Days Old. J Pediatr 2020;224:150-2.

110 Newman AM, Jhaveri R, Patel AB, et al. Trisomy 21 and coronavirus disease 2019 in pediatric patients. J Pediatr 2021;228:294-6.

111 Torres JP, Izquierdo G, Acuña M, et al. Multisystem inflammatory syndrome in children (MIS-C): report of the clinical and epidemiological characteristics of cases in Santiago de Chile during the SARS-CoV-2 pandemic. Int I Infect Dis 2020;100:75-81.

112 Saha S, Ahmed ANU, Sarkar PK, et al. The direct and indirect impact of SARS-CoV-2 infections on neonates: a series of 26 cases in Bangladesh. Pediatr Infect Dis J 2020;39:e398-e405.

113 Gale C, Quigley MA, Placzek A, et al. Characteristics and outcomes of neonatal SARS-COV-2 infection in the UK: a prospective national cohort study using active surveillance. Lancet Child Adolesc Health 2021:5:113-21.

114 Schwartz DA, Mohagheghi P, Beigi B. Spectrum of neonatal COVID-19 in Iran: 19 infants with SARS-CoV-2 perinatal infections with varying test results, clinical findings and outcomes. The Journal of Maternal-Fetal \& Neonatal Medicine 2020;2:1-10.

115 Schwartz SP, Thompson P, Smith M, et al. Convalescent plasma therapy in four critically ill pediatric patients with coronavirus disease 2019: a case series. Crit Care Explor 2020;2:e0237.

116 Almoosa ZA, Al Ameer HH, AlKadhem SM, et al. Multisystem Inflammatory Syndrome in Children, the Real Disease of COVID-19 in Pediatrics - A Multicenter Case Series From Al-Ahsa, Saudi Arabia. Cureus 2020;12:e11064.

117 Alsharrah DY, Al-Haddad F, Aljamaan S, et al. 441. clinical characteristics of pediatric SARS-CoV-2 infection and coronavirus disease 2019 (COVID-19) in Kuwait. Open Forum Infect Dis 2020:7:\$288.

118 Prata-Barbosa A, Lima-Setta F, Santos GRD, et al. Pediatric patients with COVID-19 admitted to intensive care units in Brazil: a prospective multicenter study. J Pediatr 2020:96:582-92

119 Bayesheva D, Boranbayeva R, Turdalina B, et al. COVID-19 in the paediatric population of Kazakhstan. Paediatr Int Child Health 2020:1-7.

120 Bhavsar SM, Clouser KN, Gadhavi J, et al. COVID-19 in pediatrics: characteristics of hospitalized children in New Jersey. Hosp Pediatr 2021;11:79-87.

121 Bustos-Cordova E, Castillo-García D, Cerón-Rodríguez M, et al. Clinical spectrum of COVID-19 in a Mexican pediatric population. Indian Pediatr 2020. [Epub ahead of print: 19 Dec 2020].
122 Fernández Colomer B, Sánchez-Luna M, de Alba Romero C, et al. Neonatal infection due to SARS-CoV-2: an epidemiological study in Spain. Frontiers in Pediatrics 2020;8:670

123 Storch-de-Gracia P, Leoz-Gordillo I, Andina D, et al. Clinical spectrum and risk factors for complicated disease course in children admitted with SARS-CoV-2 infection. Anales de Pediatría 2020:93:323-33.

124 Dhanalakshmi K, Venkataraman A, Balasubramanian S, et al. Epidemiological and Clinical Profile of Pediatric Inflammatory Multisystem Syndrome - Temporally Associated with SARS-CoV-2 (PIMS-TS) in Indian Children. Indian Pediatr 2020;57:1010-4

125 Falah NU, Hashmi S, Ahmed Z, et al. Kawasaki disease-like features in 10 pediatric COVID-19 cases: a retrospective study. Cureus 2020;12:e11035

126 García-Salido A, de Carlos Vicente JC, Belda Hofheinz S, et al. Severe manifestations of SARS-CoV-2 in children and adolescents: from COVID-19 pneumonia to multisystem inflammatory syndrome: a multicentre study in pediatric intensive care units in Spain. Crit Care 2020;24:1-13

127 Jain S, Sen S, Lakshmivenkateshiah S, et al. Multisystem inflammatory syndrome in children with COVID-19 in Mumbai, India. Indian Pediatr 2020:57:1015-9.

128 Kalamdani P, Kalathingal T, Manerkar S, et al. Clinical profile of SARS-CoV-2 infected neonates from a tertiary government hospital in Mumbai, India. Indian Pediatr 2020:57:1143-6.

129 Lima-Setta F, Magalhães-Barbosa MCde, Rodrigues-Santos G, et al. Multisystem inflammatory syndrome in children (MIS-C) during SARS-CoV-2 pandemic in Brazil: a multicenter, prospective cohort study. J Pediatr 2020. doi:10.1016/j. jped.2020.10.008. [Epub ahead of print: 09 Nov 2020].

130 Montoya J, Ugaz C, Alarcon S, et al. COVID-19 in pediatric cancer patients in a resource-limited setting: national data from Peru. Pediatr Blood Cancer 2021;68:e28610.

131 Önal P, Kılınç AA, Aygün F. COVID-19 in turkey: a tertiary center experience. Pediatr Int 2020.

132 Rabha AC, Oliveira Junior Flde, Oliveira TAde, et al. Clinical manifestations of children and adolescents with covid-19: report of the first 115 cases from sabará hospital infantil. Revista Paulista de Pediatria 2021;39.

133 Sethuraman U, Kannikeswaran N, Ang J, et al. Multisystem inflammatory syndrome in children associated with novel coronavirus SARS-CoV-2 presentations to a pediatric emergency department in Michigan. Am J Emerg Med 2021;39:164-7

134 Shahbaznejad L, Navaeifar MR, Abbaskhanian A, et al. Clinical characteristics of 10 children with a pediatric inflammatory multisystem syndrome associated with COVID-19 in Iran. BMC Pediatr 2020:20:1-12.

135 Webb K, Abraham DR, Faleye A, et al. Multisystem inflammatory syndrome in children in South Africa. Lancet Child Adolesc Health 2020;4:e38.

136 Zachariah P, Johnson CL, Halabi KC, et al. Epidemiology, clinical features, and disease severity in patients with coronavirus disease 2019 (COVID-19) in a children's hospital in New York City, New York. JAMA Pediatr 2020;174:e202430-e.

137 van der Zalm MM, Lishman J, Verhagen LM. Clinical experience with SARS CoV-2 related illness in children-hospital experience in Cape town, South Africa. Clinical infectious diseases: an official publication of the infectious diseases Society of America, 2020

138 Zheng $\mathrm{G}$, Wang $\mathrm{B}$, Zhang $\mathrm{H}$, et al. Clinical characteristics of acute respiratory syndrome with SARS-CoV-2 infection in children in South China. Pediatr Pulmonol 2020;55:2419-26.

139 Jiang L, Tang K, Levin M, et al. COVID-19 and multisystem inflammatory syndrome in children and adolescents. Lancet Infect Dis 2020;20:e276-88.

140 Ludvigsson JF. Systematic review of COVID-19 in children shows milder cases and a better prognosis than adults. Acta Paediatr 2020;109:1088-95.

141 Huang C, Wang Y, Li X, et al. Clinical features of patients infected with 2019 novel coronavirus in Wuhan, China. Lancet 2020;395:497-506.

142 Terry C, Mühlemann B, Veith T, et al. An analysis of SARS-CoV-2 viral load by patient age 2020.

143 Chang T-H, Wu J-L, Chang L-Y. Clinical characteristics and diagnostic challenges of pediatric COVID-19: a systematic review and meta-analysis. J Formos Med Assoc 2020;119:982-989.

144 NBS. National Bureau of statistics of China, 2019.

145 Ludvigsson JF. Case report and systematic review suggest that children may experience similar long-term effects to adults after clinical COVID-19. Acta Paediatr 2020;370. 